\title{
Brachydactyly type B
}

\author{
INSERM
}

\section{Source}

INSERM. (1999). Orphanet: an online rare disease and orphan drug data base.

Brachydactyly type B. ORPHA:93383

Brachydactyly type $B(B D B)$ is a very rare congenital malformation characterized by hypoplasia or aplasia of the terminal parts of fingers 2 to 5 , with complete absence of the fingernails. 